\title{
Optical Properties of Black Silicon with Precipitated Silver and Gold Nanoparticles
}

\author{
R. Jarimaviciute-Zvalioniene ${ }^{a, *}$, I. Prosycevas ${ }^{a}, Z_{\text {. }} \operatorname{Kaminskiene}^{a}$ \\ AND S. LAPINSKAS ${ }^{b}$ \\ ${ }^{a}$ Institute of Materials Science, Kaunas University of Technology, Savanoriu̧ pr. 271, Kaunas, Lithuania \\ ${ }^{b}$ Institute of Applied Research, Vilnius University, Sauletekio av. 10, Vilnius, Lithuania
}

\begin{abstract}
Black porous silicon is a new material with low light reflectance and high light absorbance values. Black porous silicon layers are especially useful and important in solar energy conversion. In this work black porous silicon plates were prepared by wet chemical metal-assisted method. Silver and gold nanoparticles were precipitated from colloidal silver nitrate and chloroauric acid solutions. Obtained black porous silicon samples with precipitated nanoparticles were investigated by scanning electron microscope combined with energy dispersive X-ray spectrometer, ultraviolet and visible light spectrometer, the Fourier transformation infrared spectrometer. Scanning electron microscopy and energy dispersive X-ray analysis have revealed the presence of silver and gold nanoparticles on black porous silicon surface. Silver nanoparticles size varied from 30 to $100 \mathrm{~nm}$, gold - from 20 to $70 \mathrm{~nm}$. During UV-VIS analysis significant changes in reflectance of processed black porous silicon samples were obtained. Reflectance of black porous silicon samples was lower than $10 \%$. The Fourier transform infrared analysis has revealed decrease in reflectance in far infrared region. Changes in the Fourier transform infrared spectra in "fingerprint" zone prove modification of the surface of black porous silicon layers after precipitation of metal nanoparticles.
\end{abstract}

PACS: 78.20.--e, 78,67 Bf, $78.67 \mathrm{Rb}$

\section{Introduction}

Black silicon (BS) is a new generation material, which may be useful for many applications, such as lasers, gas sensors, solar cells and etc. [1-3]. BS is a type of porous silicon with low light reflectance and high light absorbance values [4]. Etching of silicon and formation of porous surfaces can be performed by many different methods, such as electrochemical etching, ion etching, by laser influence and etc. [5-8]. But the most simple in use is chemical metal-assisted etching [9]. BS layers are especially useful and important in solar energy conversion. Forming BS layers on silicon increases the effective area and light absorbance as well as solar conversion efficiency [10]. Another new way to increase solar energy conversion is through surface plasmons, i.e., collective surface oscillations of conducting electrons in metal nanostructures. Plasmonics is a rapidly emerging subfield of nanotechnologies, which gives a possibility to control and guide light interaction with matter more effectively $[11,12]$. Noble metals like silver and gold are ideal for this purpose as they do not have many interband transitions and do not absorb much light as a result [13]. By combining black silicon with precipitated plasmonic nanoparticles in active layer has the potential to increase

* corresponding author; e-mail: renata@kauko.lt light interaction with matter more effectively and can revolutionarily change the market of solar cells.

In this work the BS plates were performed by wet chemical metal-assisted method. Silver and gold nanoparticles (NPs) were precipitated from colloidal solutions on BS surface seeking to change optical properties of BS layers.

\section{Materials and methods}

\subsection{Reagents}

All chemical reagents were used as received without further purification. For porous silicon formation hydrogen fluoride ( $\mathrm{HF}, 50 \%)$, vanadium pentoxide $\left(\mathrm{V}_{2} \mathrm{O}_{5}\right.$, certified grade), silver nitrate $\left(\mathrm{AgNO}_{3}\right)$, deionized water (made in Millipore-Q system) and nitric acid $\left(\mathrm{HNO}_{3}\right)$ were used. For silver and gold nanoparticles synthesis we have used silver nitrate $\left(\mathrm{AgNO}_{3}\right)$, chloroauric acid $\left(\mathrm{HAuCl}_{4}\right)$, sodium citrate $\left(\mathrm{C}_{6} \mathrm{H}_{5} \mathrm{O}_{7} \mathrm{Na}_{3}\right)$ and deionized water. All chemicals and solvents were obtained from Sigma-Aldrich.

\subsection{Preparation of samples}

Formation of porous silicon was carried out by modified wet chemical metal-assisted method. Firstly, $p$-type (111) silicon wafers were immersed into solution containing $5 \mathrm{ml}$ of $50 \% \mathrm{HF}, 5 \mathrm{ml}$ of deionized water and $0.01 \mathrm{~g}$ of 
silver nitrate for $10 \mathrm{~s}$ at room temperature. The yellowish mirror-like thin layer of silver was washed out with water and removed in $30 \%$ nitric acid $\left(\mathrm{HNO}_{3}\right)$ solution during $10 \mathrm{~s}$. After that, silicon wafers were immersed into etching solution, containing $5 \mathrm{ml}$ of $50 \% \mathrm{HF}, 0.5 \mathrm{~g}$ of vanadium pentoxide and $0.01 \mathrm{~g}$ of silver nitrate. Two series of BS plates were produced: etched for $10 \mathrm{~s}$ and $60 \mathrm{~s}$. Etching process was carried out at room temperature. After etching procedure, thick amorphous greenish-grey layer of silver was formed on the silicon surface. It was removed in the $30 \%$ nitric acid solution; later samples were rinsed with water and immersed into solution, containing $5 \mathrm{ml}$ of $50 \% \mathrm{HF}$ and $0.5 \mathrm{~g}$ of vanadium pentoxide (BS series 1: for $10 \mathrm{~s}$ and BS series 2: for $60 \mathrm{~s}$ ). Finally, all samples were washed thoroughly with deionized water and dried with stream of nitrogen.

Synthesis of Ag and Au NPs was done by modified Lee and Meisel method described in [14]. Colloidal solutions were produced by mixing $20 \mathrm{ml}$ of aqueous $\mathrm{HAuCl}_{4}$ $\left(10^{-3} \mathrm{M}\right)$ and $\mathrm{AgNO}_{3}\left(10^{-2} \mathrm{M}\right)$ solutions with $4 \mathrm{ml}$ of sodium citrate solution $\left(38.8 \times 10^{-3} \mathrm{M}\right)$ and boiled in the conical flask with reflux condenser for $10 \mathrm{~min}$.

\subsection{Instruments}

Surface morphology and chemical analysis of BS samples were investigated by scanning electron microscope with integrated energy dispersive X-ray spectrometer (SEM-EDX) Apollo Cam Scan $300(30$ kV, resolution $1.5 \mathrm{~nm})$.

Spectroscopic investigations of obtained BS plates were done with Avantes AvaSpec-2048 UV/VIS/NIR spectrometer in wavelength range $300-800 \mathrm{~nm}$ (spectrometer based on AvaBench-75 symmetrical Czerny-Turner construction with 2048 pixel CCD detector, resolution $1.4 \mathrm{~nm}$ ) and Nicolet model 5700 Fourier transformation infrared spectrometer (FTIR) in conjunction with a 10 Degree Specular Reflectance Accessory (spectral range $4000-400 \mathrm{~cm}^{-1}$ (reciprocal wave length), resolution $4 \mathrm{~cm}^{-1}, 64$ scans).

\section{Results and discussion}

BS samples surface morphology and cross-section were investigated by SEM. From Fig. 1a and c it can be seen that the surface of BS layers, etched for different times, differs. More cracks were formed on the surface of BS sample etched for $10 \mathrm{~s}$, comparing with the surface of BS sample etched for $60 \mathrm{~s}$. From Fig. $1 \mathrm{~b}$ and $\mathrm{d}$ it is seen that depth of porous layer of BS sample mainly depends on etching time, and was smaller for BS etched for $10 \mathrm{~s}$ $(280 \mathrm{~nm})$ than the depth of porous layer of BS sample etched for $60 \mathrm{~s}(500 \mathrm{~nm})$.

$\mathrm{Ag}$ and $\mathrm{Au}$ NPs size and distribution (Fig. 2) in colloidal solutions, were evaluated by placing $50 \mu \mathrm{l}$ of each metal colloidal solution on unprocessed, initial Si plates and dried in desiccator for $12 \mathrm{~h}$ at room temperature. As it is visible from Fig. 2a, size of $\mathrm{Ag}$ NPs varies from 30 to $100 \mathrm{~nm}$. Smaller Ag NPs tend to form clusters and

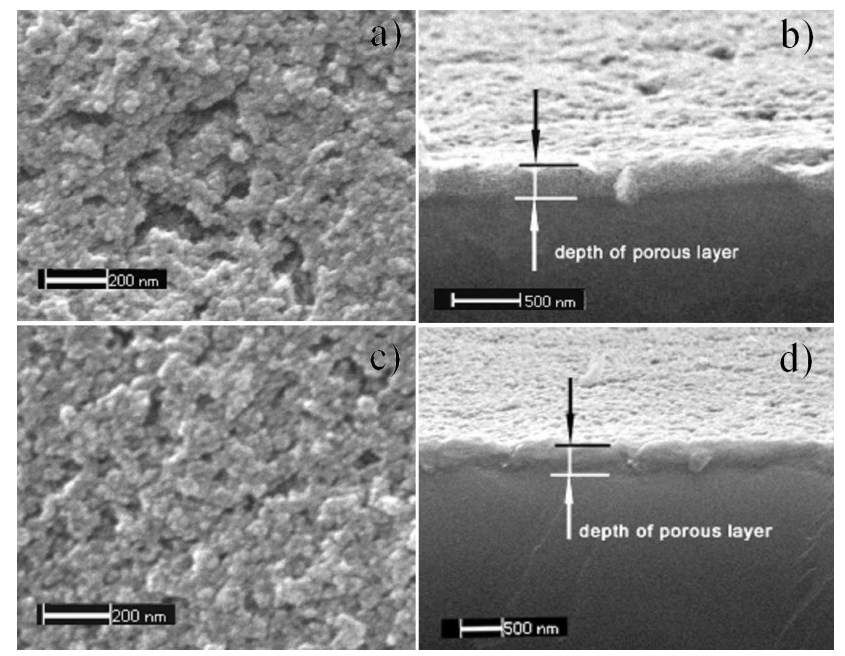

Fig. 1. SEM views of BS plates: (a) surface of BS etched for $10 \mathrm{~s}$, (b) profile view of BS etched $10 \mathrm{~s}$, (c) surface of BS etched for $60 \mathrm{~s}$, (d) profile view of BS etched for $60 \mathrm{~s}$.

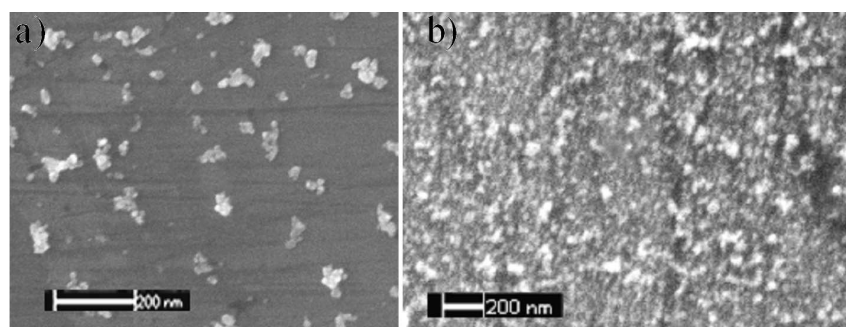

Fig. 2. SEM views of Si plates: (a) with precipitated Ag NPs, (b) with precipitated Au NPs.

agglomerates uniformly distributed on Si surface. From Fig. 2b it can be seen that Au NPs are smaller (20 to $70 \mathrm{~nm}$ ) than Ag NPs and their distribution on the surface of Si plate is denser.

Figure 3a showed that Ag NPs were bigger and mostly were distributed on the BS, which makes BS surface more rough. Ag NPs were distributed on the BS sample surface and the volume of pores. As seen in Fig. 3b, Au NPs are distributed uniformly on the surface and in pores of BS layer. $\mathrm{Au}$ NPs average size is smaller than the cracks size, and they tend to form the agglomerates inside of pores of BS layer. SEM analysis of samples has revealed that the precipitation of $\mathrm{Ag}$ and $\mathrm{Au}$ NPs on not etched silicon and BS surface can change surface morphology.

The purpose of EDX analysis was to prove the presence of $\mathrm{Ag}$ and $\mathrm{Au}$ NPs on BS surface and to evaluate their quantity. Results of EDX analysis are shown in Fig. 4. As it can be seen from Fig. 4b, the presence of Ag NPs on the surface of BS layer was detected at $3 \mathrm{keV}$ (Fig. 4b). Similar results for Ag peak position were found by Zeng and other authors [4]. The presence of Au NPs on the BS surface was detected at $2.2 \mathrm{keV}$ and $9.8 \mathrm{keV}$ (Fig. 4c). Ag quantity amounted $\approx 4 \%$ and Au quantity amounted 


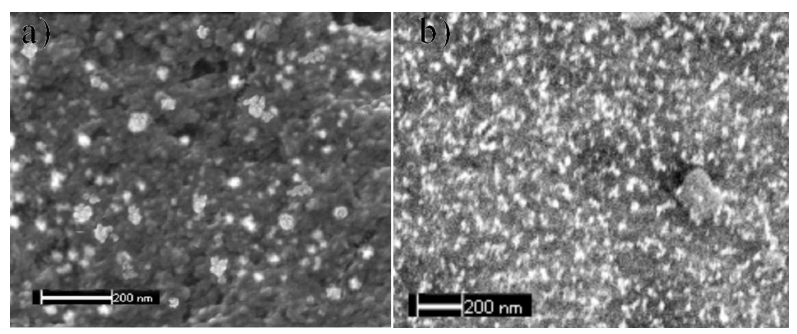

Fig. 3. SEM views of BS (etched for $10 \mathrm{~s}$ ) plates with precipitated $\mathrm{Ag}$ and $\mathrm{Au}$ NPs: (a) surface of BS-Ag, (b) surface of $\mathrm{BS}-\mathrm{Au}$.
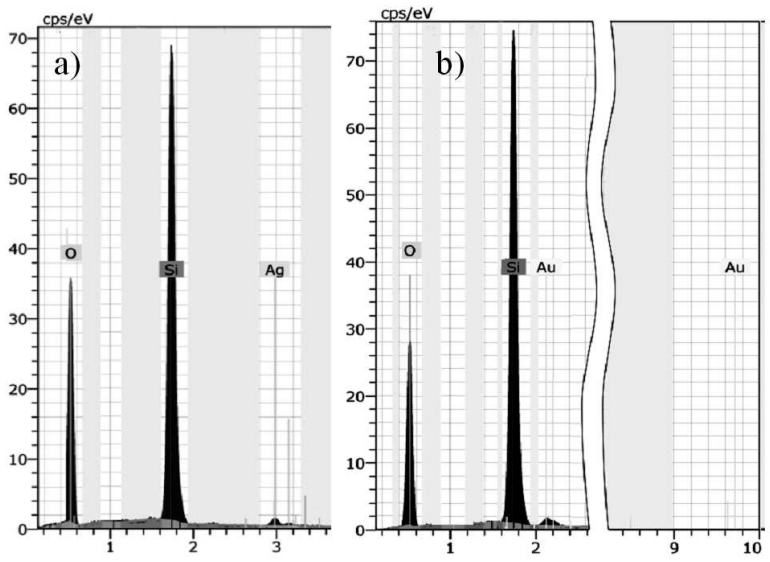

Fig. 4. EDX elemental results of BS plates: (a) BS with precipitated Ag NPs, (b) BS with precipitated $\mathrm{Au}$ NPs.

$\approx 3 \%$ from the total elemental percentage weight of all elements in all BS plates modified by Ag and Au NPs.

Typical reflectance spectra of initial silicon and BS samples modified by $\mathrm{Ag}$ and Au NPs are shown in Fig. 5. The reflectance of initial silicon after precipitation of $\mathrm{Ag}$ NPs decreased by about 20\% (curve 2). Reflectance from BS samples was lower than $5 \%$, comparing to unprocessed Si wafer, where average light reflectance was $\approx 50 \%$. Similar results for black silicon were found by other authors [4] in the same wavelength range. Comparing reflectance spectra of BS plates (Fig. 5, curves 4) with BS plates with Ag NPs (curves 5) it was observed that reflectance of BS plates with precipitated Ag NPs (BS-Ag) decreased by $\approx 3-5 \%$, which can be explained by changes of BS surface morphology.

In general, we can conclude that formation of BS was successful and precipitation of nanoparticles on its surface gives a possibility to control reflectivity of BS surfaces and can increase photoefficiency through enhanced plasmonic properties of gold and silver nanoparticles. The SPR effect of $\mathrm{Ag}$ and $\mathrm{Au}$ NPs in colloidal solution (from which there were precipitated $\mathrm{Ag}$ and $\mathrm{Au}$ NPs on BS surface) were investigated in previous study [15]. The plasmonic peaks were detected at $420 \mathrm{~nm}$ for $\mathrm{Ag}$ and $530 \mathrm{~nm}$ for $\mathrm{Au}$ NPs. These results correlate with other

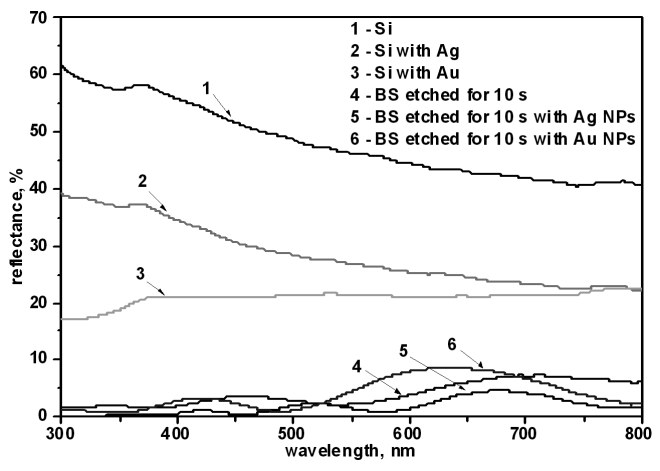

Fig. 5. UV-VIS reflectance spectra of initial silicon and BS samples (etched $10 \mathrm{~s}$ ) with precipitated Ag NPs and $\mathrm{Au}$ NPs.

authors results $[16,17]$. The changes of reflectance of samples are caused by plasmonic resonance (SPR) between the interface of metal-dielectric layer (BS surface) and by the light interference between $\mathrm{Ag}$ or $\mathrm{Au}$ NPs.

After investigation by FTIR of BS (Fig. 5, curve 4) and BS with precipitated Au NPs (curve 6) the increase to $\approx 5-10 \%$, of reflectance intensity was observed, which may be explained by more solid distribution of Au NPs on the surface of BS samples.

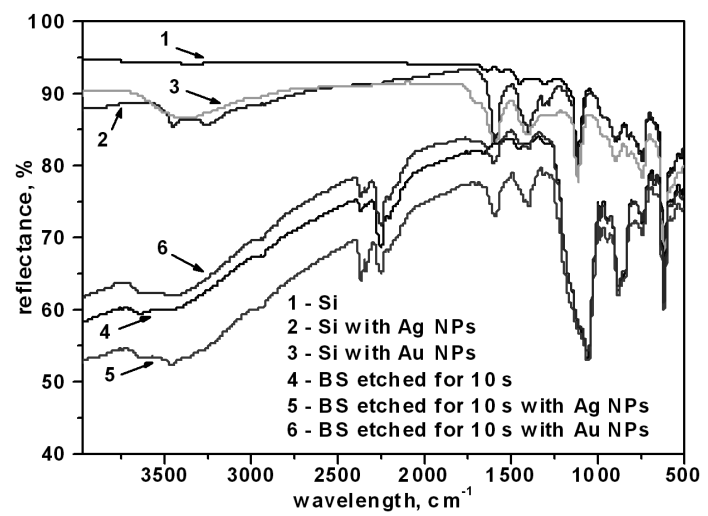

Fig. 6. FTIR reflectance spectra of initial silicon and BS samples (etched $10 \mathrm{~s}$ ) with precipitated $\mathrm{Ag}$ NPs and $\mathrm{Au}$ NPs.

FTIR reflectance spectra of silicon wafers with precipitated $\mathrm{Ag}$ and $\mathrm{Au}$ NPs exhibit similar optical properties (Fig. 6 , curve 2 and curve 3 ) and $\approx 15 \%$ lower reflectance as not etched silicon (curve 1).

From Fig. 6 it can be seen that reflectance of BS plate (curve 4), etched for $10 \mathrm{~s}$, decreases after precipitation of Ag NPs (curve 5). This can be explained by the size of Ag NPs and higher roughness of BS surface (Fig. 3a).

Precipitation of Ag NPs to BS plates, etched for different times caused changes in optical properties of BS. This is clearly visible in FTIR spectra's "fingerprint" zone $\left(\approx 1750-1250 \mathrm{~cm}^{-1}\right)$. Additional peaks of light interference after precipitation show the changes on BS surface 
and in BS layer, which may be explained by adsorption processes and chemical reactions on the BS surface.

Analyzing BS-Au samples (Fig. 6b), the reflectance of BS plates after precipitation of Au NPs increased (curves (3) and (5)) and changes in reflectance curves were almost not visible. Reflectance of BS plates modified by Au NPs can increase because of size and distribution of Au NPs on the surface of BS plates. In both cases, the size of $\mathrm{Au}$ $\mathrm{NP}$ was smaller than the size of $\mathrm{Ag} \mathrm{NP}$, and mostly they fully fulfilled the pores and cracks of BS layers, causing the surface become smoother. Appearance of additional peaks in "fingerprint" zone $\left(\approx 1750-1250 \mathrm{~cm}^{-1}\right)$ also shows changes of BS surface parameters.

Summarizing results of our work, we can state that modification of BS surface with Ag and Au NPs with plasmonic properties can change and improve optical properties of black silicon.

\section{Conclusions}

The SEM analysis of BS samples, produced by wet chemical metal-assisted method, has revealed deeper porous layer $(500 \mathrm{~nm})$ for samples etched longer time $(60 \mathrm{~s})$ and reached only $280 \mathrm{~nm}$ for samples etched $10 \mathrm{~s}$. The SEM analysis of BS plates with precipitated nanoparticles has revealed non-uniform distribution of $\mathrm{Ag}$ and $\mathrm{Au}$ NPs with diameters 50-100 nm and 20-70 nm, respectively, on BS surface and inside of pores.

EDX analysis has proved the presence of $\mathrm{Ag}$ and $\mathrm{Au}$ NPs on the surface of BS plates. Ag quantity amounted $\approx 4 \%$ and Au quantity amounted $\approx 3 \%$ from the total elemental percentage weight.

After precipitation of $\mathrm{Ag}$ and $\mathrm{Au}$ nanoparticles on initial silicon, the reflectance in the range of wavelengths $300-800 \mathrm{~nm}$ decreased by about $20 \%$ and $30 \%$, correspondingly. UV-VIS analysis has revealed very small reflectance values from BS plates $(<5 \%)$, which allows us to classify produced porous silicon plates as black silicon. After precipitation of $\mathrm{Ag}$ and $\mathrm{Au}$ NPs to BS surface, reflectance in UV-VIS region has decreased for BS-Ag samples and increased for BS-Au samples.

After FTIR analysis of BS plates, it was observed that reflectance in far infrared region has decreased for BS-Ag samples. The reflectance increased after precipitation of $\mathrm{Au}$ NPs. Additional peaks appearance in "fingerprint" zones show the significant changes of BS layer, which can be explained by adsorption processes of NPs and chemical reactions on the BS surface.

\section{Acknowledgments}

Postdoctoral fellowship is being funded by European Union Structural Funds Project "Postdoctoral Fellowship Implementation in Lithuania".

\section{References}

[1] N. Lalic, Ph.D. Thesis, KTH Royal Institute of Technology Stockholm 2000, p. 1.

[2] L. Pavesi, V. Mulloni, Appl. Phys. Lett 76, 2523 (2000).

[3] M. Lipinski, P. Panek, E. Bielanska, J. Weglowska, H. Czeternastek, Opto-Electron. Rev. 8, 418 (2000).

[4] S. Koynov, M.S. Brandt, M. Stutzmann, Appl. Phys. Lett. 88, 203107 (2006).

[5] R. Nava, J. Phys. D, Appl. Phys. 43, 455102 (2010).

[6] R. Arens-Fischer, M. Krüger, M. Thönissen, V. Ganse, D. Hunkel, M. Marso, H. Lüth, J. Porous Mater. 7, 223 (2000).

[7] M.A. Sheehy, B.R. Tull, C.M. Friend, E. Mazur, Mater. Sci. Eng. B 137, 289 (2007).

[8] R. Torres, V. Vervisch, M. Halbwax, T. Sarnet, P. Delaporte, M. Sentis, J. Ferreira, D. Barakel, S. Bastide, F. Torregrosa, H. Etienne, L. Roux, J. Optoelectron. Adv. Mater. 12, 621 (2010).

[9] K.W. Kolasinski, J.D. Hartline, B.T. Kelly, J. Yadlovskiy, Mol. Phys. 108, 1033 (2010).

[10] S.Q. Xiao, S. Xu, J. Phys. D, Appl. Phys. 44, 1 (2011).

[11] H.A. Atwater, A. Polman, Nature Mater. 9, 205 (2010).

[12] C. Photiphitak, P. Rakkwamsuk, P. Muthitamongkol, C. Sae-Kung, C. Thanachayanont, Int. J. Mech. Mater. Eng. 1, 6 (2010).

[13] V.S. Tiwari, O. Tovmachenko, G.K. Darbha, W. Hardy, J.P. Singh, P.C. Ray, Chem. Phys. Lett. 446, 77 (2007).

[14] A. Šileikaitė, J. Puišo, I. Prosyčevas, S. Tamulevičius, Mater. Sci. (Medžiagotyra) 15, 21 (2009).

[15] Z. Kaminskiene, I. Prosycevas, R. Jarimaviciute-Zvalioniene, S. Lapinskas, Advanced Materials and Technologies, the 13th Int. Conf. School, Technologija, Kaunas 2011, p. 135.

[16] E. Hutter, J.H. Fendler, D. Roy, J. Phys. Chem. B 105, 11159 (2001).

[17] L.B. Scaffardi, N. Pellegri, O. de Sanctis, J.O. Tocho, Nanotechnology 16, 158 (2005). 